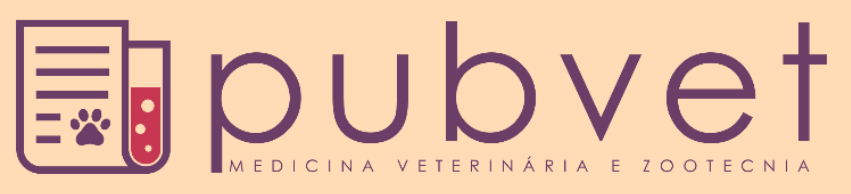

https://doi.org/10.31533/pubvet.v14n5a572.1-4

\title{
Leite ultra fresh
}

\section{Bruna Pessine Novaes de Lima ${ }^{\ominus}$, Carolina de Carvalho ${ }^{1}$, Dayla de Souza Negrini ${ }^{1}{ }^{\ominus}$, Franciele da $\operatorname{Cruz}^{1}{ }^{\ominus}$, Lara Roberta da Silva ${ }^{\ominus}$, Marcelo Henrique de Paiva ${ }^{\ominus}$, Scheilla Thais Cavalheiro ${ }^{1}$, $^{\circ}$ Raimundo Nonato Rabelo ${ }^{2} \bullet$}

${ }^{1}$ Discente em Medicina Veterinária do Centro Universitário da Fundação de Ensino Octávio Bastos - UNIFEOB, São João da Boa Vista - SP, Brasil. ${ }^{2}$ Docente do curso de Medicina Veterinária na Instituição de Ensino Octávio da Silva Bastos - UNIFEOB, São João da Boa Vista - SP, Brasil. E-mail:raimundo.rabelo@unifeob.pro.br

*Autor para correspondência, E-mail: pessinevet@gmail.com

Resumo. O leite possui uma composição nutricional balanceada, que inclui todos os nutrientes essenciais para o crescimento e desenvolvimento das espécies mamíferas. Porém nele se encontra uma grande diversidade de micro-organismos, inclusive de patógenos, logo, a sua forma de industrialização requer cuidados específicos. Esses cuidados precisam de acompanhamento técnico desde o início de sua produção, ainda no curral, até se chegar nas grandes indústrias. Todavia como se sabe, o leite compõe uma variabilidade de microorganismos, cabe ao processo de industrialização fazer com que o mesmo se torne adequado para o consumo humano, de forma que os laticínios tenham como opção a elevação de temperatura para que assim ocorra a destruição dos patógenos presentes. A indústria com seu processo de evolução criou vários métodos para executar esses processos de neutralização de patógenos e o objetivo deste trabalho é evidenciar a técnica ultra high temperature (UHT), que consiste em elevar o calor de forma intensa por um curto período.

Palavras chave: bactocentrifugação, leite, uht, ultra fresh

\section{Ultra-fresh milk}

Abstract. The milk has a balanced nutritional composition that includes all the nutrients essential for the growth and development of mammalian species. But there is a great diversity of microorganisms, including pathogens, then its form of industrialization requires specific care. These care needs technical support from the beginning of its production, still in the corral, until reaching the large industries. However, as it is known, milk composes a variability of microorganisms, it is up to the industrialization process to make it suitable for human consumption, so that way dairy products have the option of raising the temperature so that it occurs destruction of present pathogens. The industry with its evolution process has created several methods to perform these pathogen neutralization processes and the objective of this work is to highlight the ultra-high temperature (UHT) technique, which consists of raising the heat intensely for a short period of time.

Keywords: bacterocentrifugation, milk, uht, ultra-fresh

\section{Introdução}

O leite é por sua composição considerado um dos alimentos mais completos em condições nutricionais e fundamentais para dieta humana, mas pela mesma razão, estabelece um excelente substrato para o desenvolvimento de uma grande diversidade de microrganismos, inclusive os patogênicos (Closs et al., 2012). O leite é um ambiente propício para o crescimento de inúmeros microrganismos devido a sua formação rica em carboidratos, proteínas e gorduras combinados com o seu $\mathrm{pH}$ próximo da neutralidade (Antunes, 2014). O elevado número de microrganismos vivos no leite 
cru denota a presença de falhas nos métodos de manipulação, higienização e sanidade do animal, sendo capaz de afetar a qualidade e reduzir a vida útil do produto final (Nörnberg et al., 2009).

Um dos processos fundamentais na industrialização do leite é o da eliminação dos microrganismos. Para a destruição da microbiota presente no leite é utilizado pelos laticínios o método de tratamento térmico. Um desses processos que tem se destacado atualmente na indústria de laticínios é o ultra-high temperatura (UHT) ou ultra alta temperatura (UAT) (Cunha, 2001; Grave, 2012).

Segundo Tetra Pak (1996), UHT é uma técnica para a preservação de alimentos líquidos por meio da sua exposição ao calor intenso por um rápido período de tempo, destruindo os micro-organismos do produto. O leite UHT, habitualmente denominado de leite "longa vida", é um produto de fácil comercialização e consumo (Closs et al., 2112). Após o processo de industrialização o leite resulta em diversos tipos para o consumo, fiscalizado por normas de inspeção industrial e sanitária adequadas (Closs et al., 2112).

O tratamento térmico pode ser executado de dois modos diferentes sendo, o tratamento direto, com injeção de vapor no leite (operação conhecida como uperização) ou pela dispersão do leite em uma câmara de vapor. No tratamento indireto, o leite é aquecido por um trocador de calor (trocador de placas ou um sistema tubular) (Freitas, 2015). O tratamento térmico no processo UHT é um de fluxo constante, em que o leite é preaquecido, homogeneizado antes ou após a esterilização, esterilizado, resfriado e embalado assepticamente. Qualifica pela aplicação de temperaturas entre 140 e $150{ }^{\circ} \mathrm{C}$ durante 2 a 4 segundos, para esterilização de todo o produto. O Regulamento Técnico de Identidade e Qualidade de Produtos Lácteos determina como leite UHT "o leite homogeneizado que foi submetido, durante 2 a 4 segundos, a uma temperatura entre 130 e $150{ }^{\circ} \mathrm{C}$, por um processo térmico de fluxo contínuo, imediatamente resfriado a uma temperatura inferior a $32{ }^{\circ} \mathrm{C}$ e envasado sob condições assépticas em embalagens estéreis e hermeticamente fechadas" (Brasil, 1996 \& Cunha, 2001).

A empresa Tetra Pak do Brasil desenvolveu uma nova variante tecnológica que defende a opção de aplicar uma centrifugação degerminadora (bactocentrifugação) durante a etapa de pré-aquecimento do leite, consecutivamente antes do tratamento UHT direto. Esse sistema (Sistema Ultra Fresh ${ }^{\circledR}$ ) permite minimizar a carga térmica aplicada durante a etapa de ultra pasteurização, aprimorando o perfil sensorial do leite UHT e diminuindo seus custos processuais, para a obtenção de um produto de vida de prateleira de 4 meses (Revillion, 2004). A qualidade é o maior objetivo em todos os ramos profissionais. Se, por um lado, este fator é responsável pela busca do aperfeiçoamento contínuo, por outro, assegura a sobrevivência na competitividade entre os mercados (Closs et al., 2012). Dessa forma, o presente trabalho tem como objetivo apresentar uma revisão de literatura sobre o leite UHT com enfoque no sistema Ultra Fresh.

\section{Leite ultra fresh}

O leite é um fluido secretado pelas glândulas mamárias das fêmeas mamíferas, tendo como função primordial ser a fonte exclusiva das necessidades funcionais dos mamíferos jovens, não podendo ser substituída (Oliveira, 2009). Na alimentação humana, o leite bovino é uma excelente fonte de energia, proteínas e gordura, dispondo de uma composição completa e balanceada, mas também é um substrato ideal para o desenvolvimento de diversos grupos de microrganismo, como bactérias, fungos e vírus (Busatta et al., 2005).

De matéria gordurosa o leite é uma emulsão, com elementos na forma coloidal e em suspensão, sendo a água seu maior constituinte, apresenta-se branco e opaco, de sabor doce e reação iônica próxima da neutralidade (Oliveira, 2009). É um dos alimentos mais completos, sua microbiota e composição química, torna o leite um produto altamente perecível, tornando necessário para sua conservação, tratamentos adequados higiênicos e tecnológicos (Bartoszewicz et al., 2008). Segundo Oliveira (2009), a carga bacteriana do leite interfere na qualidade da matéria-prima e por sua vez, na qualidade do produto obtido. Contagens elevadas de microrganismos no leite cru evidenciam a existência de falhas nos procedimentos de manipulação, higienização e sanidade do animal, podendo comprometer a qualidade e diminuir a vida de prateleira do produto final (Nörnberg et al., 2009).

Uma das técnicas para a conservação dos alimentos é a aplicação de calor para a redução da carga de micro-organismos, aptos para deteriorar o produto ou causar doenças infecciosas. A aplicabilidade 
de processos para a conservação por calor, está condicionada às características de cada alimento e sua particularidade, assim como as características dos micro-organismos a serem eliminados, sendo importante também a observação das condições necessárias para manter as características sensórias do alimento (Silva, 2000). A aplicação de altas temperaturas para a conservação do leite está estabelecida no efeito que este aumento causa nos micro-organismos presentes, eliminando-os em sua maioria. Altas temperaturas resultam na desnaturação de proteínas e na inativação de enzimas fundamentais à sobrevivência e desenvolvimento dos micro-organismos. A principal finalidade do tratamento térmico é diminuir riscos à saúde dos consumidores e retardar alterações indesejáveis no produto, aumentando sua vida de prateleira (Sanchez, 2005). Para garantir a qualidade dos alimentos a utilização do tratamento térmico tem preenchido um espaço relevante na evolução da tecnologia alimentar. Devido à sua tecnologia tornou-se um produto de destaque e de fácil consumo e comercialização (Bastos, 1999).

Esporos resistentes às altas temperaturas podem sobreviver ao tratamento UHT, e subsequentemente crescendo no leite estocado (Grave, 2012). O gênero Bacillus também merece destaque por possuir microrganismos formadores de esporos, como o Bacillus sporothermodurans, e por serem resistentes aos tratamentos térmicos aplicados ao leite (Chen et al., 2003; Sanjana et al., 2019; Sørhaug \& Stepaniak, 1997).

De acordo com Tetra Pak (2004) o sistema Ultra Fresh é uma tecnologia para ser aplicada no leite UHT, juntamente com o processo de ultra pasteurização. O Ultra Fresh ou Bactofuga é uma centrífuga que opera em alta rotação e tem por finalidade a separação e retirada de micro-organismos ativos, microorganismos esporulados e células somáticas. Este processo é aplicado após pré-aquecimento do leite e antecede a ultra pasteurização. O equipamento para a transformação do leite em ultra fresh possui um motor trabalhando em alta rotação, a alta rotação proporciona ao sistema uma força de centrífuga de até cinco mil vezes a força gravitacional, promovendo um alto poder de separação. Características como o tamanho da partícula a ser separada, viscosidade do produto centrifugado, diferença de densidade entre os componentes separados são determinados na eficiência do equipamento, variando de acordo com o produto. No equipamento utilizado, o leite entra pela parte inferior, passa por discos perfurados no corpo da centrífuga e deste saem duas correntes, uma sendo o leite bactofugado e outra o resíduo da descarga, que ocorre de acordo com uma programação em intervalos definidos de tempo, durante o período de operação (Tetra Pak, 2004). Os resultados obtidos com o emprego do sistema ultra fresh variam de acordo com as bactérias envolvidas na composição do leite e a temperatura escolhida para a realização da bactofugação. Para esporos de Clostridium a porcentagem de eliminação das bactérias é de $99,1 \%$ a $78{ }^{\circ} \mathrm{C}$ (Bergere et al., 1969). Prata (1998) relata que a aplicação de tratamentos térmicos é importante na evolução da tecnologia alimentar, sendo eficiente sempre que respeitado o binômio tempo $\mathrm{x}$ temperatura, para que sejam eliminados os micro-organismos indesejáveis e preservadas as características originais e valor nutricional do produto.

\section{Considerações finais}

O leite UHT é um dos processos fundamentais na industrialização do leite, utilizado para esterilização de alimentos através do aquecimento e, imediatamente a seguir, do resfriamento, com o intuito de destruir a microbiota presente no leite, pois o mesmo é um ambiente propício para o crescimento de inúmeros microrganismos devido a sua formação rica em carboidratos, proteínas e gorduras combinados com o seu pH próximo da neutralidade. O Ultra Fresh é um sistema que combina tratamentos físico (de centrifugação, para redução de bactérias e células somáticas) e térmico (de injeção direta de vapor), garantindo economia no processo de ultrapasteurização e ressaltando o sabor do leite, sem alterar sua composição.

\section{Referências bibliográficas}

Antunes, V. C. (2014). Uso de microfiltração para melhoria da qualidade e extensão da vida de prateleira de leite pasteurizado. Brazilian Journal of Food Technology, 17(1), 75-86.

Bartoszewicz, M., Hansen, B. M., \& Swiecicka, I. (2008). The members of the Bacillus cereus group are commonly present contaminants of fresh and heat-treated milk. Food Microbiology, 25(4), 588596.

Bastos, M. S. R. (1999). Leite longa vida UHT: aspectos do processamento e identificaçäo dos pontos 
críticos de controle. Higiene Alimentar, 13(66/67), 32-36.

Bergere, J. L., Le Bars, D., \& Commissaire, J. (1969). La bactofugation du lait et l'élimination des spores de Clostridium tyrobutyricum. Le Lait, 49(488), 507-519.

Brasil. Ministério da Agricultura, do Abastecimento e da Reforma Agrária. Portaria No 146, de 07 de março de 1996. Regulamento Técnico de Identidade e Qualidade dos Produtos Lácteos. Diário Oficial [da República Federativa do Brasil], Brasília, 11 de março de 1996.

Busatta, C., Valdruga, E., \& Cansian, R. L. (2005). Ocorrência de Bacillus sporothermodurans em leite UAT integral e desnatado. Food Science and Technology, 25(3), 408-411.

Chen, Y., Qin, B., Teubner, K., \& Dokulil, M. T. (2003). Long-term dynamics of phytoplankton assemblages: Microcystis-domination in Lake Taihu, a large shallow lake in China. Journal of Plankton Research, 25(4), 445-453.

Closs, E., Wolshick, M., \& Souza, C. F. V. (2012). Comparação de qualidade dos leites UHT e UHT ultra fresh de uma usina de leite da região do Vale do Taquari/RS. Revista Higiene Alimentar, 26(192/193), 98-103.

Cunha, M. F. (2001). Revisão: leite UHT e o fenômeno de gelatinização. Boletim Do Centro de Pesquisa de Processamento de Alimentos, 19(2), 341-352.

Freitas, J. A. (2015). Introdução à hygiene e conservação das matérias-primas de origem animal. Atheneu Editora.

Grave, E. (2012). Análise da eficiência do uso de Bactofugação na remoção de micro-organismos em amostras de leite. Trabalho de Conclusão de Curso (Bacharelado em Química Industrial) - Centro Universitário Univates, Lajeado.

Nörnberg, M. F. B. L., Tondo, E. C., \& Brandelli, A. (2009). Bactérias psicrotróficas e atividade proteolítica no leite cru refrigerado. Acta Scientiae Veterinariae, 37(2), 157-163.

Oliveira, M. M. (2009). Tecnologia dos produtos lácteos funcionais. Atheneu Editora.

Prata, L. F. (1998). Leite UHT: soluçäo ou problema? Uma análise da situaçäo. Higie, 12(54), 10-15.

Revillion, J. P. P. (2004). Análise dos sistemas setoriais de inovação das cadeias produtivas de leite fluido na França e no Brasil. Universidade Federal do Rio Grande do Sul.

Sanchez, C. P. P. (2005). Ocorrência de Bacillus cereus, avaliação de sua resistência térmica em sistema contínuo e seu controle em leite UHT. Tese (Doutorado em Ciência dos Alimentos) - Faculdade de Engenharia de Alimentos, Universidade Estadual de Campinas.

Sanjana, M. C., Ramachandra, B., \& Prabha, R. (2019). Isolation of biosurfactant producing Bacillus spp. from milk samples. The Pharma Innovation Journal, 8(3), 690-602.

Silva, J. A. (2000). Tópicos da tecnologia de alimentos. Varela Editora e Livraria Ltda.

Sørhaug, T., \& Stepaniak, L. (1997). Psychrotrophs and their enzymes in milk and dairy products: quality aspects. Trends in Food Science \& Technology, 8(2), 35-41.

Tetra Pak. (1996). Dairy processing handbook. Lund, Sweden.

Tetra Pak. (2004). Manual Operacional da Centrífuga Ultra Fresh.

Recebido: 7 de novembro, 2019.

Aprovado: 5 de dezembro, 2019.

Disponível online: 17 de junho, 2020.

Licenciamento: Este artigo é publicado na modalidade Acesso Aberto sob a licença Creative Commons Atribuição 4.0 (CC-BY 4.0), a qual permite uso irrestrito, distribuição, reprodução em qualquer meio, desde que o autor e a fonte sejam devidamente creditados. 